\title{
Debate
}

\section{The family rule: a reply to Alderson}

\author{
D M Foreman Keele University, Staffordshire
}

\begin{abstract}
In her commentary, Alderson makes four major criticisms of the family rule. She claims that: consent must be explicit; that consenting parties should be reasonably equal; that the concept of a family rule adds little to current understanding, and that the effect of applying the concept in practice will be to impair the consenting process. However, there are other important examples of implicit consent in daily life, and consent between unequals is common and unexceptionable. The family rule establishes an unequivocal ethical base for the role of children, parents and practitioners in the consenting process, which is sorely needed. This base structures practitioners' interventions towards children in an appropriately empowering manner. Therefore, Alderson's critical objections fail.
\end{abstract}

(Fournal of Medical Ethics 1999;25:499-500)

Keywords: Consent; children; ethics; family

\section{The response}

The raft of criticisms Alderson makes about the family rule includes four that are potentially fatal to the concept or its application. First, she claims that consent must be explicit. Secondly, consenting parties must be reasonably equal. These challenge the consensual nature of parent-child relations assumed in the family rule. Thirdly, she claims that the family rule adds little to current understanding or practice. This makes the family rule pointless. Fourthly, she claims that the impact of the family rule will be negative on almost every aspect of obtaining consent in children. This makes the family rule harmful. Clearly, all four need direct answer.

\section{CAN MEANINGFUL CONSENT BE IMPLICIT?}

Our society is full of examples of implicit consent. There is a legally important concept of consensual sexual activity: sexual activity imposed on someone without his or her agreement, or who is incompetent to agree, can result in criminal prosecution of the perpetrator. However, our most vivid experiences of consensual sexual activity are unlikely to include a statement to the effect of "do you agree to engage in the following sexual activities with me, clearly understanding their implications and consequences". Just as in the family rule, sexual consent is inferred from our behaviour, judged against our capacity.

\section{CAN THERE BE CONSENT BETWEEN UNEQUALS?}

The stronger party in an unequal relationship does not have to coerce the weaker into an agreement. Such uncoerced agreements are surely consensual. "Policing by consent" is a useful concept to consider here, as it is another example of how consenting to a rule has primacy over consenting to an event. We are happy to see policemen patrolling our neighbourhood, but when they give us a parking ticket, we say they should be "out chasing criminals". Then-being good citizens-we pay our fine.

DOES THE FAMILY RULE ADD LITTLE TO OUR CURRENT UNDERSTANDING OR PRACTICE?

The family rule gives parents an explicit ethical role in consent, as custodians of their children's autonomy. Without such a role, parents can be completely disregarded. An example of this can be seen in the first four paragraphs of Alderson's commentary. They completely fail to mention parents as doing anything more than agreeing with doctors or children, despite claiming to set out the key issues involving consent in children. Most practitioners would recognise parents as having a role that goes far beyond this. However, as Gillick and its aftermath have shown, we still struggle to define the value of that role, as well as its limitations. The family rule begins to define both, in a way that can be operationalised in practice.

IS THE FAMILY RULE LIKELY TO IMPEDE THE CONSENTING PROCESS?

Parents are custodians of the child's autonomy, not owners. Therefore, they are ethically constrained; for example, they must make rational decisions in the child's best interests. Furthermore, children may claim their autonomy over any 
issue once they have the capacity to do so. All of these negotiations are likely to be implicit. Therefore, acceptance of the concept of the family rule imposes a considerable investigative task on the practitioner seeking consent for an intervention. The practitioner must assess: whether the parents are fulfilling their custodianship ethically; whether the child has the capacity to reclaim the right to consent for the intervention, and whether the child actually wishes to do so. It is difficult to see how an increased demand for sensitive assessment combined with an inclusive, child-centred approach will impede the consenting process.

\section{Conclusion}

There is not space here to cover the more minor criticisms, which do not challenge the integrity of the family rule concept itself. Likewise, there is not space to discuss how the family rule could help manage the various difficult questions mentioned at the end of Alderson's commentary, though they are adumbrated in the main paper. I am glad that Alderson now agrees that the difficulties are too subtle for legal solutions. This contrasts with Alderson and Montgomery previous recommendation of a legally enforceab?e code of conduct for obtaining consent from children. The family rule can structure professional practice to address these issues. The lof can then step in, as in other circumstances, when this practice has been negligently observed.

Dr D M Foreman, MB, MSc, MRCPsych, $\stackrel{\tilde{N}_{L}}{\perp s}$ Consultant/Senior Lecturer in Child and Adolescent Psychiatry, Keele University. Address for correspont ence: Department of Psychiatry, Keele Universig, Thornburrow Drive, Hartshill, Stoke-on-Trent S $7 Q B$.

\section{References}

1 Anonymous. Gillick v W Norfolk and Wisbech ANA. All Eng land Law Reports 1985: 402.

2 Alderson P, Montgomery J. Health care choices: making decisions about children. London: Institute for Public Policy Research, 1996: 86. 